\title{
Laparoscopic ultrasonic dissectors: technology update by a review of literature
}

This article was published in the following Dove Press journal:

Medical Devices: Evidence and Research

\author{
Rajesh Devassy' \\ Sadaf Hanif ${ }^{\prime}$ \\ Harald Krentel ${ }^{2}$ \\ Hugo C Verhoeven ${ }^{2}$ \\ Luz Angela Torres-de la \\ Roche $^{2}$ \\ Rudy Leon De Wilde ${ }^{2}$ \\ 'Dubai London Clinic \& Specialty \\ Hospital, Dubai, UAE; ${ }^{2}$ Clinic \\ of Gynecology, Obstetrics and \\ Gynecological Oncology, University \\ Hospital for Gynecology, Carl von \\ Ossietzky University, Pius-Hospital \\ Oldenburg, Oldenburg, Germany
}

Correspondence: Rudy Leon De Wilde Clinic of Gynecology, Obstetrics and Gynecological Oncology, Pius Hospital, University Hospital for Gynecology, Carl von Ossietzky University Oldenburg, Georgstrasse 12, 26121 Oldenburg, Germany

Tel +49 44I 229 I524

Email rudy-leon.dewilde@pius-hospital.de

\begin{abstract}
The evolution of minimally invasive surgery has brought forward the appearance of new advances in the course of the most recent couple of years and has introduced energybased devices. The newest among them today are the ultrasonically activated devices, which are utilized with a great deal of components in-play, including ergonomics and financial aspects amid surgery. The methodology embraced was finding significant investigations through studies from PubMed, Medline and Google Scholar on current ultrasonic dissectors, which are Ethicon's Harmonic Scalpel (ACE ${ }^{\circledR}$ ), Covidien's Sonicision ${ }^{\mathrm{TM}}$ (SNC), Conmed's SonoSurg ${ }^{\circledR}$ (SS) and Olympus's Thunderbeat ${ }^{\circledR}$, to describe their efficacy in terms of vessel sealing speed, vessel burst pressure, visibility, operation time and thermal speed. We found postmarketing evidence to determine which device exhibits the better performance. Animal studies showed that emissivity values and maximum temperatures for coagulation are similar among devices but maximum cutting temperatures are significantly different: $\mathrm{ACE}=191.1^{\circ} \mathrm{C}, \mathrm{SNC}=227.1^{\circ} \mathrm{C}$, $\mathrm{SS}=184.8^{\circ} \mathrm{C}(p<0.001)$. Cooling times are significantly different among devices: $35.7 \mathrm{~s}$ for $\mathrm{ACE}, 38.7 \mathrm{~s}$ for SNC and $27.4 \mathrm{~s}$ for SS $(p<0.001)$. Cooling times of passive jaws to reach $60^{\circ} \mathrm{C}$ after activation were also significantly different: $25.4 \mathrm{~s}$ for ACE, $5.7 \mathrm{~s}$ for SNC, and $15.4 \mathrm{~s}$ for SS $(p<0.001)$. The perfect device would unify brilliant hemostatic outcomes with visual sharpness while permitting none or insignificant thermal damage at the place of use.
\end{abstract}

Keywords: laparoscopy, ultrasonic dissectors, thermal damage, energy devices

\section{Introduction}

Ultrasonically activated devices (USADs) are widely used as cutting devices in laparoscopic surgeries because of their quick and simple control of bleeding without significant complications due to denaturation of protein, which occurs by mechanically breaking of the hydrogen bonds in protein molecules when the blade vibrates. ${ }^{1}$ USADs might reduce operating time, blood loss and hospital stays. ${ }^{1}$

The introduction of ultrasonic energy into surgical dissecting devices was a significant technological breakthrough in minimally invasive surgery (MIS) in the 1990s. Although the use of these devices is an acquired skill to those only familiar with electrical or radiofrequency (RF) energy-based technologies, the learning curve is steep, ${ }^{2}$ specially for junior surgeons with limited access to minimal invasive procedures as a leading surgeon. Moreover, they offer coagulation, cutting, dissecting and grasping as an all-in-one system with some of the smallest thermal footprints around. ${ }^{1}$ The versatility and safety profiles make ultrasonic energy a compelling technology to consider and to be aware of their technological updates. ${ }^{2}$ 
The aim of the present review on the currently used laparoscopic ultrasonic dissectors is to describe the efficacy and potential intraoperative pitfalls of these devices in terms of vessel sealing speed, vessel burst pressure, mesenteric cutting speed, tip grasping force, tip thickness, dissecting force, visibility, operation time and thermal speed.

\section{Methods}

This literature review was performed following the Preferred Reporting Items for Systemic Reviews and Meta-Analyses (PRISMA) statement. ${ }^{3}$ Only randomized controlled or cohort in-human studies and comparative in-animal studies published after January 2015 in Medline, PubMed and Google Scholar were primarily considered for inclusion. No new in-human studies but one in-animal study comparing USADs were found. One single-cohort study of patients undergoing laparoscopic surgery with the use of the combined ultrasonic and bipolar energy device Thunderbeat ${ }^{\mathbb{B}}$ (TB) was found. Therefore, further review articles were considered to discuss other technical aspects of interest.

\section{Results}

Currently, the most used ultrasonic dissectors are Harmonic Scalpel (ACE ${ }^{\circledR}$; Ethicon Endo-Surgery Inc., Cincinnati, OH, USA), Sonicision ${ }^{\mathrm{TM}}$ (SNC; Covidien, a Medtronic company, Mansfield, MA, USA), SonoSurg ${ }^{\circledR}$ (SS; Olympus USA, Center Valley, PA, USA) and TB (Olympus Corporation, Tokyo, Japan). A brief description of each device is presented before discussing their differences.

The ACE is a surgical instrument used to cauterize and cut the tissue at the same time: ${ }^{1}$ instead of electric current, it utilizes ultrasonic vibrations. It can slice through thicker tissue with a high accuracy and a low surgical smoke production. By vibrating at 55,500 Hz, the ACE coagulates and cuts vessels up to $7 \mathrm{~mm}$ in diameter. ${ }^{4}$ Frequent vibrations of the tissue particles create stress and friction, which produce heat and cause denaturation of protein. This system causes negligible vitality reduction to the encompassing tissue, constraining collateral damage as it cuts tissues while sealing the edges. The framework is ordinarily made out of a handheld ultrasonic transducer, generator, hand switch, foot pedal and scalpel.

The SNC cordless ultrasonic dissection device is a threepiece system that includes an ultrasonic dissector hand piece and a reusable generator, with battery. ${ }^{1}$ The hand piece is a single-patient-use (disposable) device with a $39-\mathrm{cm}, 5-\mathrm{mm}$ diameter $360^{\circ}$ rotational shaft that culminates in a $14.5-\mathrm{mm}$ active blade with an inactive cutting anvil. Both the generator and battery are snap-in components that fit into the handle and can be reprocessed and reused for up to 100 sterilization cycles. The handle has a traditional pistol-grip style with a depressible lever to open and close the device's jaws, and a single dual-mode energy button allows surgeon to define the minimal and maximal energy to use when the respective button is pressed. This enables ultra-high-frequency mechanical motion to transect, dissect and coagulate tissue with vessels up to $5 \mathrm{~mm}$ in diameter. ${ }^{2,4}$ The SNC device is designed to be both ergonomic and intuitive for the user; it can be inserted and extracted through a compatible $5 \mathrm{~mm}$ trocar. A unique characteristic of the device is that it functions without the need for external power cords and transducer cables. SNC generators and batteries are prepared and attached to the dissector as a disposable component. When assembled, electrical power supplied by the battery pack is available to be converted into ultrasonic energy in the generator. The surgeon achieves the clinical intended use when pressure is applied to tissue placed between the clamping jaw and the exposed portion of the probe, while activating ultrasonic energy using a two-stage button.

The ultrasonic energy delivery system SS uses highfrequency mechanical vibrations produced by an electrical energy source coupled to a piezoceramic transducer in a closed-loop control manner. ${ }^{1}$ High-frequency vibrations from the transducer are mechanically coupled via a titanium horn to a mechanism that heats tissue between jaws to produce a seal. The jaws, being reusable, make it unique in economic viability. However, the mechanism of the jaws with lesser pressure on the tissue makes the coagulation and hemostasis more applicable in dissection than in vascular sealing.

The TB system simultaneously delivers ultrasonically generational heat energy and electrically generated bipolar energy from a single, multifunctional instrument. ${ }^{1}$ This integration takes advantage of each type of energy: the capacity to quickly cut tissue with ultrasonic energy and to make vessel seals with bipolar energy. It is capable of sealing vessels up to $7 \mathrm{~mm}$ in diameter while also providing fast cutting speed. TB's fine jaw design provides precise dissection and forceful grasping. Its always-available bipolar energy ensures hemostasis without the need of simultaneous cutting. ${ }^{1}$ This device is an engaging, safe option for cutting, coagulation and tissue dissection amid surgery and can reduce the operating time.

\section{Assay of visual obstruction with respect to surgical plume}

Modern USADs are considered to be safe and effective. ${ }^{1,4,5}$ Important differences exist in comparison to electrocautery 
devices mainly in the quantity and type of particles contained in the smoke produced during their use. Surgical smoke produced by electrocautery during laparoscopic surgery will probably stay in the abdomen more time than that after an open surgery. It is composed of breathable aerosol (particles of size $\leq 4.5 \mu \mathrm{m})$ and cell material $(\geq 7 \mu \mathrm{m}){ }^{6}$ When compared to electrocautery, the smoke produced by USADs is composed of tissue, blood and blood degradation products that could be identified up to $40 \mathrm{~cm}$ from the point of production. It is also reported that higher smoke $\left(>1 \times 10^{7}\right.$ particles $\left./ \mathrm{mL}\right)$ during ACE use is produced when it works simultaneously on various tissues, being 17-23 times higher when fatty tissue is included. ${ }^{7,8}$

Surgical smoke reduces laparoscopic visibility, but its concentration in the peritoneal cavity differs among dissector and hemostatic devices. The fog formation has been assessed using a fixed box furnished with a light-emanating diode and a phototransistor with infrared light transmission during the procedure. ${ }^{9}$ Less smoke emission was observed when the dissection power was low but dissection times were longer. The visibility is mainly affected by the amount of persistent particles than by the particle size. Monopolar-based instruments have the poorest relative visibility compared to bipolar or ultrasonic devices ( 0.026 vs. 0.887 and 0.801 , respectively). ${ }^{10}$

Despite utilizing the same ultrasonic innovation, it has been reported that the cutting edge geometry of the device also affects the smoke production. ${ }^{11}$ USADs with straight sharp edges have more reliable oscillations and create more laminar flow than those with curved blades. Laminar stream causes less visual block by dispersing the aerosol downward and helps it to disseminate rapidly, while turbulent smoke is dispersed inconsistently across the abdominal cavity. It causes visibility obstruction $0.3 \mathrm{~s}$ after activation and clears after 2 s. $^{11}$

Surgical smoke production by USADs is also related to the mode of use, being increased in coagulation than in the cut mode and is maximal when the device is used in the highest settings. ${ }^{12}$ During coagulation, the ACE generates five times more smoke than SNC, whereas SS creates the lower amounts. ${ }^{10}$ According to the area, SS smoke covers $0.21 \%$ of the operating field, whereas SNC covers $4.8 \%$ of the field and ACE covers $26.63 \%$ of the field. ${ }^{13}$ The SNC produces up to five times less surgical plume than TB, despite the latter has a higher flexibility with speedier cutting speed, comparable bursting pressure and worthy spread. ${ }^{14}$ In maximal settings, the differences between devices are greater than in the coagulation mode (Figure 1). ${ }^{11}$ The ACE produces more smoke than SNC and SS; the lowest amount is generated by SS. In addition, SNC exhibited the fastest dissection speed and smoke production.

\section{Lateral thermal damage to surrounding tissues}

Another matter of concern when using energy-dependent shear devices is the lateral thermal damage to surrounding tissues that could lead to inadvertent damage of adjacent organs or structures. ${ }^{15-17}$ Advanced USADs are believed to be safer than instruments that use diathermy energy, as they integrate piezoelectric transducers that actuate a vibration

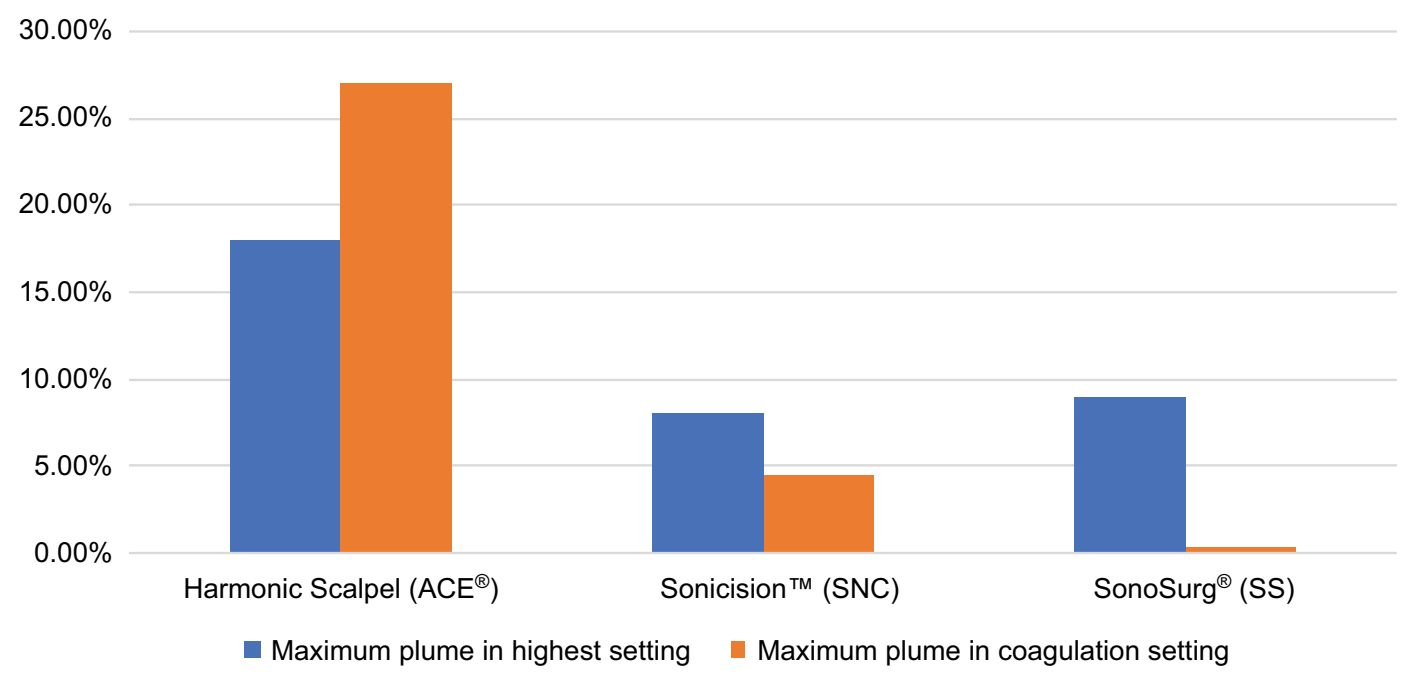

Figure I Surgical plume production of different ultrasonic devices.

Note: Reprinted by permission from Springer Nature: Surg Endosc. Kim FJ, Sehrt D, Pompeo A, Molina WR. Laminar and turbulent surgical plume characteristics generated from curved- and straight-blade laparoscopic ultrasonic dissectors. 20I4;28(5):I674-167. Copyright 20I4." 
frequency at the functional tip and transduce a lower amount of energy to the tissue, ensuing reduced lateral thermal damage and penetration depth, owing to lower temperatures..$^{417-19}$ Advanced USADs built hemostasis by tamponing and sealing the vessels with a protein coagulum at a temperature range of $50-100^{\circ} \mathrm{C},{ }^{21}$ achieving excellent hemostasis through confined coagulation with a minimal lateral thermal damage., ${ }^{4,17-19}$

In addition, European Surgical Research (2009) reported that coagulation necrosis is greater if the utilization is nonstop rather than separated or reconnected. Studies on porcine and rodent abdominal walls showed that the lateral thermal tissue damage is directly related to duration of application, being greater when a long continuous period is utilized irrespectively if the USADs are used in the standard output power and likewise when the USADs' application is not followed by a short pause between applications. ${ }^{18}$ Moreover, the performance of currently laparoscopic USAID's is different in terms of vessel sealing speed (mean time), vessel burst pressure (mmHg), visibility, operation time and degree of thermal damage (Table 1). ${ }^{4,20,21}$ Being reported that the TB device allows a faster surgery with higher burst pressure and minimal lateral thermal spread than other devices. ${ }^{22}$

Different studies showed that ACE had the lowest mean burst pressure and the least thermal spread and smoke than other laparoscopic vessel ligation devices, including bipolar devices such as LigaSure (LIG), Gyrus PK (GPK) and EnSeal PTC (ES). Light microscopy and morphometric imaging examination revealed that the lateral tissue thermal harm after ACE application is related to the duration of application, with a mean harm width of $0.0522 \pm 0.0097 \mathrm{~mm}$ after a $5 \mathrm{~s}$ application, $0.1544 \pm 0.0419 \mathrm{~mm}$ after a $10 \mathrm{~s}$ application and $0.1020 \pm 0.0430 \mathrm{~mm}$ after a regimen of two successive $5 \mathrm{~s}$ applications. ${ }^{17}$ Lateral tissue thermal harm is more prominent if the ACE application time is constant as opposed to of a similar aggregate length with a short midpoint intrusion.
Other studies show that lateral thermal damage produced by the ACE at an output power of 5/5 was greater than that at an output power of $3 / 5 \cdot{ }^{17-25}$ At the highest power setting, slightly less thermal injury was caused by the ACE $(127.48 \mu \mathrm{m})$ than by the LIG $(144.18 \mu \mathrm{m})$; however, this difference was not found to be significant (Table 2). ${ }^{23,24}$

In a comparative study of monopolar, bipolar diathermy, ACE and LIG, temperatures generated in the adjacent tissue and $1 \mathrm{~cm}$ away from the treated tissue were recorded. ${ }^{23}$ The grade of lateral thermal spread is different within instruments, power settings and application times. After 5-s activation at the highest power setting, different temperatures were recorded at the tips of monopolar plume, bipolar diathermy, ACE and LIG instruments: $78.9^{\circ} \mathrm{C}, 41.9^{\circ} \mathrm{C}, 47.6^{\circ} \mathrm{C}$ and $44.2^{\circ} \mathrm{C}$, respectively. Applying monopolar diathermy $(10 \mathrm{~s}$ at $40 \mathrm{~W}$ ) resulted in a temperature recording of $59.2^{\circ} \mathrm{C}$ in tissues $1 \mathrm{~cm}$ away from the tip of the instrument. Monopolar diathermy ensured the highest temperatures and the greatest degree of thermal spread in tissues. ${ }^{23}$

Table 2 Thermal damage at different power settings among different laparoscopic shears

\begin{tabular}{|c|c|c|}
\hline Cor & $\begin{array}{l}\text { Mean value } \\
(\mu \mathrm{m})\end{array}$ & $p$ value \\
\hline (ACE ${ }^{\circledR}$; output power $\left.3 / 5\right)$ & 90.42 & \\
\hline $\begin{array}{l}\text { Monopolar diathermy vs. ACE (output } \\
\text { power } 5 / 5 \text { ) }\end{array}$ & 27.48 & $<0.001$ \\
\hline Monopolar diathermy vs. LigaSure (LIG) & 215.79 vs. 144.18 & $<0.001$ \\
\hline $\begin{array}{l}\text { ACE (output power } 3 / 5 \text { ) vs. ACE (output } \\
\text { power } 5 / 5 \text { ) }\end{array}$ & 90.42 & 0.001 \\
\hline ACE (output power $3 / 5$ ) vs. LIG & 90.42 vs. 127.48 & $<0.001$ \\
\hline ACE (output power $5 / 5$ ) vs. LIG & 127.48 vs. 144.18 & 0.39 \\
\hline ACE (output power $5 / 5$ ) vs. SonoSurg ${ }^{\circledR}$ (SS) & 90.49 vs. 117.6 & $<0.001$ \\
\hline
\end{tabular}

Note: Based on Sutton PA, Awad S, Perkins AC, Lobo DN. Comparison of lateral thermal spread using monopolar and bipolar diathermy, the Harmonic scalpel and the Ligasure. Br J Surg. 2010;97(3):428-433, with permission from John Wiley and Sons. ${ }^{23}$ and Družijanić N, Pogorelić Z, Perko Z, Mrklić I, Tomić S. Comparison of lateral thermal damage of the human peritoneum using monopolar diathermy, Harmonic scalpel and LigaSure. Can J Surg. 2012;55(5):317-321..$^{44}$

Table I Performance of current ultrasonic dissectors

\begin{tabular}{|c|c|c|c|c|}
\hline $\begin{array}{l}\text { Device } \\
\text { perfomance }\end{array}$ & $\begin{array}{l}\text { Ethicon's Harmonic Scalpel } \\
\left(\mathrm{ACE}^{\circledR}\right)\end{array}$ & $\begin{array}{l}\text { Covidien's } \\
\text { Sonicision }^{\mathrm{TM}} \text { (SNC) }\end{array}$ & Conmed's SonoSurg $^{\circledR}$ (SS) & $\begin{array}{l}\text { Olympus's } \\
\text { Thunderbeat }^{\circledR} \text { (TB) }\end{array}$ \\
\hline $\begin{array}{l}\text { Vessel sealing speed } \\
\text { (mean time in s) }\end{array}$ & $3.3 \pm 1.0$ & $5.2 \pm 1.7$ & $\begin{array}{l}\text { Not applicable (N/A; alignment of } \\
\text { the jaws does not approximate) }\end{array}$ & $2.43 \pm 0.76$ \\
\hline $\begin{array}{l}\text { Vessel burst pressure } \\
(\mathrm{mmHg})\end{array}$ & Lowest mean burst pressure & $\begin{array}{l}\text { Low mean burst } \\
\text { pressure }\end{array}$ & Moderate mean burst pressure & $\begin{array}{l}\text { Highest mean burst } \\
\text { pressure }\end{array}$ \\
\hline $\begin{array}{l}\text { Vessel sealing } \\
\text { (maximum diameter) }\end{array}$ & Up to $7 \mathrm{~mm}$ & Up to $5 \mathrm{~mm}$ & Up to $5 \mathrm{~mm}$ & Up to $7 \mathrm{~mm}$ \\
\hline Visibility & Mist production affecting visibility & Less mist production & Smoke production affecting visibility & Unimpaired visibility \\
\hline Thermal spread & $<\mathrm{l} \mathrm{mm}$ & $\mathrm{l} \mathrm{mm} \pm 0.5 \mathrm{~mm}$ & $2 \mathrm{~mm}$ & Least lateral thermal spread \\
\hline
\end{tabular}




\section{Adaptability of energy-dependent shear devices}

Adaptability of a USAD is characterized as the execution of the surgical instrument in view of five factors: tissue fixation (bursting pressure), hemostasis (safe coagulation), cutting (precise tissue section), dissection (precise tissue separation) and tissue control (thermal spread). In a comparative study on different USADs, including TB, ACE, LIG and ES, Yorkshire pig vessels of $2 \mathrm{~cm}$ length and little $(2-3 \mathrm{~mm})$, medium (4-5 $\mathrm{mm}$ ) and substantial (6-7 mm) width were used to measure their adaptability. ${ }^{14}$ By using a score from 1 to $5(5=$ best $)$, the flexibility score was higher $(p<0.01)$ and analyzation time was shorter utilizing TB in comparison to the other three devices $(p<0.01)$. Bursting pressure was similar between all devices. Thermal spread at surgery was comparable among TB and ACE $(p=0.4167), \mathrm{TB}$ and ES $(p=0.6817)$ and TB and LIG $(p=0.8254)$. Significant differences in thermal spread were noted among ES and $\mathrm{ACE}(p=0.0087)$ and $\mathrm{ACE}$ and LIG $(p=0.0167)$. The study inferred that TB has a higher adaptability with faster dissection speed and comparable bursting pressure and thermal spread.

\section{Emissivity and cutting temperature}

In relation to cutting temperature and cooling times of different ultrasonic shears, in a comparative trial, it was demonstrated that SNC improves cutting with hotter blades, while the SS had more precise coagulation effects by slower heating. In this study, the temperature was measured by means of an infrared thermal imager and the tissues were microscopically examined after reaching $60^{\circ} \mathrm{C}$ of temperature. ${ }^{26}$ Emissivity values, which is the produced thermal radiation, were similar among devices: $\mathrm{ACE}=0.49 \pm 0.01 \mathrm{~mm}, \mathrm{SNC}=0.40 \pm 0.00 \mathrm{~mm}$ and $\mathrm{SS}=0.39$ $\pm 0.01 \mathrm{~mm}$. Maximum cutting temperatures were significantly different $\left(\mathrm{ACE}=191.1^{\circ} \mathrm{C}, \mathrm{SNC}=227.1^{\circ} \mathrm{C}, \mathrm{SS}=184.8^{\circ} \mathrm{C}[p\right.$ $<0.001]$ ), but maximum temperatures for coagulation did not fluctuate significantly among devices $(p=0.490)$. The cooling times to reach $60^{\circ} \mathrm{C}$ after activation were significantly different among devices: $35.7 \mathrm{~s}$ for ACE, $38.7 \mathrm{~s}$ for SNC and $27.4 \mathrm{~s}$ for SS $(p<0.001)$. The cooling times of passive jaws to reach $60^{\circ} \mathrm{C}$ after activation were also significantly different: $25.4 \mathrm{~s}$ for ACE, $5.7 \mathrm{~s}$ for SNC and $15.4 \mathrm{~s}$ for SS $(p<0.001)$. Furthermore, the jaw-edge geometry of the device allows having different emissivity and cutting temperature profiles (Table 3 ). ${ }^{26}$

\section{Discussion}

The increasing expertise in MIS demands advances in surgical devices. Specifically, current USADs, Ethicon's ACE, Covidien's SNC, Conmed's SS and Olympus's TB, exhibit differences
Table 3 Comparison of emissivity and maximum cutting temperature in different ultrasonic shears

\begin{tabular}{lll}
\hline Type of dissector & $\begin{array}{l}\text { Emissivity } \\
(\mathbf{m m})\end{array}$ & $\begin{array}{l}\text { Maximum cutting } \\
\text { temperature }\left({ }^{\circ} \mathbf{C}\right)\end{array}$ \\
\hline${\text { Harmonic Scalpel }\left(\mathrm{ACE}^{\circledR}\right)}^{\mathrm{TM}}$ & $0.49 \pm 0.01$ & 191.10 \\
Sonicision $^{\mathrm{TM}}(\mathrm{SNC})$ & $0.40 \pm 0.00$ & 227.1 \\
SonoSurg $^{\circledR}$ (SS) & $0.39 \pm 0.01$ & 184.8 \\
\hline
\end{tabular}

Notes: Maximum coagulation temperatures did not differ significantly among devices $(p=0.490)$. Reprinted by permission from Springer Nature: Surg Endosc. Kim FJ, Sehrt D, da Silva RD, Gustafson D, Nogueira L, Molina WR. Evaluation of emissivity and temperature profile of laparoscopic ultrasonic devices (blades and passive jaws). 2015;29(5): I 179-1 184. Copyright 2014. ${ }^{26}$

in design, smoke production and cutting temperature, which are important to know when planning a surgery. The latest introduction of cordless USADs enhances handling capacity and agility, giving surgeons freedom of movement in the operation theaters, eliminating the need to handle cables on the sterile field and enhancing surgeon's focus on the patient. In addition, the intuitive dual-mode energy activation control offers minimum and maximum power modes within one button, allowing easy transition between energy modes, rapid tissue dissection and safe hemostasis. The reusable handheld generator works with a reusable battery; therefore, it is not required to connect the device to a bulky generator outside the surgical field. ${ }^{13}$

Formation of surgical smoke is potentially detrimental and dangerous; ${ }^{25,31}$ thus, factors influencing increased smoke and aerosol generation should be considered preoperatively to guarantee security and adequacy, which are type of tissuethick flaps, fat contents, coagulation necessity, curved blades and monopolar devices. ${ }^{12}$ An ideal USAD will dissect and coagulate tissue with negligible thermal damage to the surrounding tissues while allowing optimal visualization by producing negligible aerosol particles. ${ }^{12,27,28}$ The USADs coagulate and transect vessels by converting electric energy into ultrasonic vibration through a piezoelectric or magnetic transducer, which induces heat between the two jaws of the instrument during contact ${ }^{18,29}$ with a subsequent production of aerosol particles that in turn spread into the abdominal cavity and into the operation room environment when trocars are removed. ${ }^{25,31}$ Surgical smoke produced by electrocautery is composed of tissue detritus, volatile organic hydrocarbons, toluene and methyl propene and other carcinogenic particles, while aerosol particles produced by USADs contain a higher amount of cells, tissue and blood detritus. ${ }^{18,29}$ During oncological surgery, the presence of intact cancer cells in the smoke that in turn could spread the tumor into the abdominal cavity is a matter that is not yet well investigated. ${ }^{30}$ Although advanced USADs generate less surgical aerosol, it impairs the visibility during laparoscopy, requiring frequent cleaning 
of the scope to remove the adhering particles, frequent cleaning of the scope is required, affecting safety and surgical time. ${ }^{6,25,31}$ Additionally, it has been reported that inhalation of surgical smoke affects the health of surgeons. ${ }^{32,33}$ Therefore, it is recommended that surgical smoke should be removed and filtered during open and endoscopic procedures, as well prior to removing cannulas and trocars..$^{30,32,33}$

While using the USADs, it is vital to consider the lateral thermal damage to the surrounding structure for the safety and integrity of the tissues in terms of power settings (higher output-higher damage) and duration of application ( $5 \mathrm{~s}$ application followed by a $5 \mathrm{~s}$ pause and then reapplication). ${ }^{1}$ Ultrasonic energy conveyed through ACE appeared to be sheltered and to deliver insignificant harm to the encompassing tissue. High settings and delayed ultrasonic tissue dissection may produce significant heat and tissue harm. Particularly in the region of delicate tissues or organs, a lateral thermal harm occurs when the ACE application time surpasses 10 s. ${ }^{17,18}$ Thus, the degree of lateral thermal spread depends on the type of instrument and its appropriate utilization. ${ }^{1}$ Energy-related injuries are also associated with the required temperature of cutting and cooling. ACE can cut through thicker tissue with greater precision, and TB has a faster dissection speed. The emissivity dimensions of ACE are significantly higher in comparison to $\mathrm{SS}$ and also the device requires more time to cooling than SNC and SS $(p=0.001)$. This is of special interest when surgeons are operating near sensitive tissues or organs, and thermal injuries, such as big vessels, biliary ducts or ureter, should be avoided

Other observed differences are related to burst pressure, vessel sealing and cutting velocities. ${ }^{4,20,22}$ TB exhibits fast vessel sealing speeds with the highest burst pressure, whereas ACE is equally fast by sealing but with the lowest mean pressure and lower cutting velocity; SS has a moderate mean bursting pressure. ACE and TB are able to seal vessels up to $7 \mathrm{~mm}$, whereas SNC and SS seal vessels of low caliber (up to $5 \mathrm{~mm}$ ). ${ }^{4}$ In the clinical context, surgeons should be aware of the vessel diameter and sealing limits of the device to avoid hemorrhage during or after surgery. Large vessels require multiple sealing applications before cutting in the middle of the seals, which should not be too close to avoid thermal damages that cannot be detected by the laparoscopic lens. ${ }^{14}$

Although USADs are widely adopted in MIS, the present review highlights the limited postmarketing clinical evidence once an USAD is approved for human uses. Actually, there is no new clinical trial registered for developing devices in the International Clinical Trials Registry Platform, European
Union Clinical Trials Register or German Clinical Trials Register. Further innovations should improve the pivotal safety aspects and the efficiency of MIS in terms of instrument handling, surgical ergonomics, thermal effect, costs and patient outcomes.

\section{Conclusion}

The current laparoscopic USADs, Ethicon's ACE, Covidien's SNC, Conmed's SS and Olympus's TB, are distinctive in terms of their clinical performance such as vessel sealing speed, vessel burst pressure, mesenteric cutting speed, tip grasping force, tip thickness, dissecting force, visibility, operation time and thermal speed. These technologically advanced ultrasonic shears have given appreciable results and opened a new era to the field of minimally access surgery. However, the lack of evidence in relation to the surgeon's learning curve, costbenefit ratio and safety during oncological procedures exists. More evidence is required for a better adoption of these novel technologies into clinical practice and insurance coverage, as well to avoid litigation from unknown adverse outcomes.

\section{Author contributions}

All authors made substantial contributions to conception and design, acquisition of data, or analysis and interpretation of data; took part in drafting the article or revising it critically for important intellectual content; gave final approval of the version to be published; and agree to be accountable for all aspects of the work.

\section{Disclosure}

RD has conflicts of interest in terms of Covidien supporting the educational activities in UAE. The authors have no other conflicts of interest and no personal financial relationships with any of the companies whose products are reviewed here.

\section{References}

1. Devassy R, Gopalakrishnan S, De Wilde R. Surgical efficacy among laparoscopic ultrasonic dissectors: are we advancing safely? A review of literature. J Obstet Gynaecol India. 2015;65(5):293-300.

2. Greenberg J. Sonicision cordless ultrasonic dissection device. Rev Obstet Gynecol. 2013;6(2):100-101.

3. Liberati A, Altman DG, Tetzlaff J, et al. The PRISMA statement for reporting systematic reviews and meta-analyses of studies that evaluate healthcare interventions: explanation and elaboration. $B M J$. 2009;339:b2700.

4. Newcomb WL, Hope WW, Schmelzer TM, et al. Comparison of blood vessel sealing among new electrosurgical and ultrasonic devices. Surg Endosc. 2009;23(1):90-96.

5. Sotiropoulos G, Stamopoulos P, Charalampoudis P, Molmenti E, Voutsarakis A, Kouraklis G. Totally laparoscopic left hepatectomy using the torsional ultrasonic scalpel. World $J$ Gastroenterol. 2013;19(35):5929-5932. 
6. DesCoteaux JG, Picard P, Poulin EC, Baril M. Preliminary study of electrocautery smoke particles produced in vitro and during laparoscopic procedures. Surg Endosc. 1996;10(2):152-158.

7. Ott DE, Moss E, Martinez K. Aerosol exposure from an ultrasonically activated (Harmonic) device. J Am Assoc Gynecol Laparosc. 1998;5(1):29-32.

8. Perko Z, Mimica Z, Druzijanić N, et al. Harmonic scalpel in laparoscopic surgery. Lijec Vjesn. 2004;126(9-10):246-250. Croatian.

9. Schneider A, Doundoulakis E, Can S, Fiolka A, Wilhelm D, Feussner H. Evaluation of mist production and tissue dissection efficiency using different types of ultrasound shears. Surg Endosc. 2009;23(12):2822-2826.

10. Weld KJ, Dryer S, Ames CD, et al. Analysis of surgical smoke produced by various energy-based instruments and effect on laparoscopic visibility. J Endourol. 2007;21(3):347-351.

11. Kim FJ, Sehrt D, Pompeo A, Molina WR. Laminar and turbulent surgical plume characteristics generated from curved- and straight-blade laparoscopic ultrasonic dissectors. Surg Endosc. 2014;28(5):1674-1677.

12. Kim F, David S, Pompeo A, Molina W. Comparison of surgical plume among laparoscopic ultrasonic dissectors using a real-time digital quantitative technology. Surg Endosc. 2012;26(12):3408-3412.

13. Kim F, Sehrt D, Molina W, Pompeo A. Clinical use of a cordless laparoscopic ultrasonic device. JSLS. 2014;18(3):e2014.001153.

14. Milsom J, Trencheva K, Monette S, et al. Evaluation of the safety, efficacy, and versatility of a new surgical energy device (Thunderbeat) in comparison with Harmonic ACE, LigaSure V, and EnSeal devices in a porcine model. J Laparoendosc Adv Surg Tech A . 2012;22(4):378-386.

15. Sartori PV, De Fina S, Colombo G, et al. Ligasure versus ultracision in thyroid surgery: a prospective randomized study. Langenbecks Arch Surg. 2008;393(5):655-658.

16. Kim FJ, Chammas MF, Gewehr E, et al. Temperature safety profile of laparoscopic devices: Harmonic ACE (ACE), Ligasure V (LV), and plasma trisector (PT). Surg Endosc. 2008;22(6):1464-1469.

17. Perko Z, Pogorelić Z, Bilan K, et al. Lateral thermal damage to rat abdominal wall after Harmonic scalpel application. Surg Endosc. 2006;20(2):322-324.

18. Pogorelić Z, Perko Z, Druzijanić N, Tomić S, Mrklić I. How to prevent lateral thermal damage to tissue using the Harmonic scalpel: experimental study on pig small intestine and abdominal wall. Eur Surg Res. 2009;43(2):235-240.

19. Diamantis T, Kontos M, Arvelakis A, et al. Comparison of monopolar electrocoagulation, bipolar electrocoagulation, ultracision, and Ligasure. Surg Today. 2006;36(10):908-913.
20. Fagotti A, Vizzielli G, Fanfani F, et al. Randomized study comparing use of Thunderbeat technology vs standard electrosurgery during laparoscopic radical hysterectomy and pelvic lymphadenectomy for gynecologic cancer. J Minim Invasive Gynecol. 2014;21(3): $447-453$.

21. Copel M. Performance of Sonicision Cordless Ultrasonic Dissection Device compared to the Harmonic ACE. Covidien (Covidien Test Report no. 2-105-10)

22. Obonna GC, Mishra RK. Differences between Thunderbeat, LigaSure and Harmonic scalpel energy system in minimally invasive surgery. World J Laparosc Surg. 2014;7(1):41-44.

23. Sutton PA, Awad S, Perkins AC, Lobo DN. Comparison of lateral thermal spread using monopolar and bipolar diathermy, the Harmonic scalpel and the Ligasure. Br J Surg. 2010;97(3):428-433.

24. Družijanić N, Pogorelić Z, Perko Z, Mrklić I, Tomić S. Comparison of lateral thermal damage of the human peritoneum using monopolar diathermy, Harmonic scalpel and LigaSure. Can J Surg. 2012;55(5):317-321.

25. Emam T, Cuschieri A. How safe is high-power ultrasonic dissection? Ann Surg. 2003;237(2):186-191.

26. Kim FJ, Sehrt D, da Silva RD, Gustafson D, Nogueira L, Molina WR. Evaluation of emissivity and temperature profile of laparoscopic ultrasonic devices (blades and passive jaws). Surg Endosc. 2015;29(5):1179-1184.

27. Tsirline VB, Lau KN, Swan RZ, et al. Evaluation of an innovative, cordless ultrasonic dissector. Surg Innov. 2013;20(5):524-529.

28. Hashizume M, Sugimachi K, Ueno K. Laparoscopic splenectomy with an ultrasonic dissector. J Med. 1992;327(6):438.

29. Cimino WW, Bond LJ. Physics of ultrasonic surgery using tissue fragmentation: part I. Ultrasound Med Biol. 1996;22(1):89-100.

30. Steinemann DC, Lamm SH, Zerz A. Efficacy and safety of combined ultrasonic and bipolar energy source in laparoscopic surgery. $J$ Gastrointest Surg. 2016;20(10):1760-1768.

31. Den Boer KT, de Jong T, Dankelman J, Gouma DJ. Problems with laparoscopic instruments: opinions of experts. J Laparoendosc Adv Surg Tech A. 2001;11(3):149-155.

32. Fitzgerald JE, Malik M, Ahmed I. A single-blind controlled study of electrocautery and ultrasonic scalpel smoke plumes in laparoscopic surgery. Surg Endosc. 2012;26(2):337-342.

33. Clements R, Palepu R. In vivo comparison of the coagulation capability of SonoSurg and Harmonic ACE on $4 \mathrm{~mm}$ and $5 \mathrm{~mm}$ arteries. Surg Endosc. 2007;21(12):2203-2206.
Medical Devices: Evidence and Research

\section{Publish your work in this journal}

Medical Devices: Evidence and Research is an international, peerreviewed, open access journal that focuses on the evidence, technology, research, and expert opinion supporting the use and application of medical devices in the diagnosis, monitoring, treatment and management of clinical conditions and physiological processes. The identification of novel devices and optimal use of existing devices which will lead to improved clinical outcomes and more effective patient management and safety is a key feature. The manuscript management system is completely online and includes a quick and fair peer-review system. Visit http://www. dovepress.com/testimonials.php to read real quotes from authors. 